\title{
Three-dimensional spatial and temporal distributions of dust in roadway tunneling
}

\author{
Haifei Yao $^{1,2}$ (1) $\cdot$ Haiyan Wang ${ }^{1,2} \cdot$ Yanchuan $\mathrm{Li}^{1,2} \cdot$ Lei Jin $^{1,2}$
}

Received: 25 May 2019/Revised: 9 December 2019/Accepted: 17 January 2020/Published online: 7 February 2020

(C) The Author(s) 2020

\begin{abstract}
To study the three-dimensional spatial and temporal distributions of dust in tunneling roadways, and to solve the problems of inadequate time and limited number of monitoring points, this paper designs a device for the real-time monitoring and storage of data on the concentrations of dust at multiple measuring points in the same section of a tunnel. The proposed device can measure the total concentration of dust and that of respirable dust in real time at different instances and locations, and using different working procedures. These measurements are used to study the temporal and spatial migration of dust. The results show that there was a sharp fluctuation zone $0-25 \mathrm{~m}$ from the heading face, about 25-40 m was high speed subsidence, beyond $40 \mathrm{~m}$ was gentle subsidence, The change of respiratory dust is much smoother. At different distances from the heading face, the total dust concentration exhibited a process of "violent oscillation-rapid descent-stable descent," while the respirable dust exhibited a process of "fluctuating ascent-gradual subsidence." Changes in the concentrations of total dust and respirable dust dust were consistent at different positions in the same section of the tunnel. The concentration of dust near the wall was low, and those along the sidewalk and air duct of the roadway were slightly higher than in the middle. The concentration of dust farther down the air duct decreased more slowly than that in the remaining lines of measurement. Small amounts of dust featuring large particles settled quickly. High concentrations of dust were observed to be intermittent, and the background value of dust concentration within $100 \mathrm{~m}$ of heading face was between 0.5 and $3 \mathrm{mg} / \mathrm{m}^{3}$.
\end{abstract}

Keywords Excavation roadway $\cdot$ Dust $\cdot$ Real-time monitoring $\cdot$ Spatial and temporal distribution

\section{Introduction}

Yao et al. (2011) conclude that dust is one of the five major sources of disasters in coal mines, and two kinds of risks are posed by it. (Ghose and Majee 2000), The first is the risk of coal dust explosion that can cause loss of life and damage equipment, (Witt et al. 2002), the second is long-

Haifei Yao

yhf8000@163.com

1 Mine Safety Technology Branch of China Coal Research Institute, Beijing 100013, China

2 State Key Laboratory of Coal Resource High Effective Mining \& Clean Utilization, China Coal Research Institute, Beijing 100013, China term harm to human health from respirable dust, Yao et al. (2014), which can result in pneumoconiosis among miners. (Wang and Levy 2003), to reduce the concentration of dust underground, Descamps et al. (2005), researchers and Hou et al.(2006),engineers have carried out a large number of theoretical and experimental studies, and Yao et al. (2009a, b) have made such proposals as the coal seam water injection (Jiang et al. 2001), high-pressure spray dust removal (Zhang 2012), the dust collection drum, negative pressure dust removal, and gas-water spray dust removal. However, owing to a poor understanding of rules of the temporal and spatial evolution of downhole dust, research on and implementation of technical measures to prevent the collection of dust remain inadequate. 
A literature review (Zou et al. 2014) has shown that Chinese studies on the distributions of dust in mines mainly use two methods. The first is to arrange test points on site (Nie et al. 2013) or a simulated roadway to obtain the law of distribution of dust by measuring the dust concentration at each point. The second method uses the principle of twophase gas-solid flow to describe the law of motion of dust in space through a numerical simulation (Hu et al. 2013). Such research (Lu et al. 2012) has accumulated useful content for research on the rules of dust migration, and Qin et al. (2014) has played an important role in guiding the implementation of measures to prevent and reduce dust. However, some limitations persist, mainly in the following aspects: (1) The number of points at which dust is measured at sites is limited, sampling time is long, and data obtained from these sampling points in a given time are difficult to use to describe the dynamic distribution of dust concentration in mining operations. (2) Differences occur in the distribution of dust concentration at different locations of the same section of an underground roadway. However, the values at certain points contradict the results of conventional studies, which leads to an insufficiently detailed and representative description of the law of distribution of dust. (3) The richness and accuracy of numerical simulations is premised on the accuracy of the established model and the set boundary conditions, both of which depend on the diversity and accuracy of the field data collected. However, it is difficult for a general weighing method to satisfy the above requirements with limited samples.

In light of the above, this paper develops a device that can monitor and store dust concentration at multiple measuring points in the same section of a roadway in real time to monitor dust in three dimensions. It helps obtain the law of the three-dimensional (3D) spatial and temporal distributions of roadway dust by analyzing the monitoring data. This study can help guide technical measures for dust control and removal.

\section{Purpose of experiment}

\subsection{Monitoring dust concentrations at different times}

To obtain the distribution of the concentration of dust over the entire working process before, during, and after tunneling, a sensor is placed underground for a long time to measure this distribution.

\subsection{Tests of dust concentration at different locations}

To test the distribution of dust concentration at different positions of the heading face, the sensor is designed not to move forward with the advancing heading face. This ensures that it can measure dust concentration at different positions of the heading face. To test the concentration at different positions of the section, five sensors were placed in each section to test dust concentrations at the same time. This also helped verify the measurements.

\subsection{Testing for different types of dust}

The sensor can be used for the real-time measurement of total dust and respirable dust in the roadway during tunneling. Two dust samplers were used to test the respirable and total dust at the same position. A test was carried out twice a day during tunneling at a location according to the layout of the sensors. The results were compared and calibrated according to proportional conversion.

\section{Experimental location and method}

\subsection{Experimental location}

This study was carried out on the 120-slot digging face of Sect. 1 of the Tingnan Mine. The working face was arranged in the No. 4 coal seam, with a total engineering volume of $1475 \mathrm{~m}$, a rectangular section of the roadway, a net width of $6.1 \mathrm{~m}$, and a net height of $4.1 \mathrm{~m}$. The S200A tunneling machine was used. Tunneling was carried out using a layering method. The average thickness of coal seam was $8.2 \mathrm{~m}$ and its average dip angle was $4^{\circ}$. The coal and rock mainly consisted of bright coal of carbon fiber sheets containing a pyrite structure, layered structure, and a staggered fracture with a Platt's hardness coefficient of $f=1.95-2.7$.

Press-in ventilation was used, and a local ventilator was installed in the path of flow of fresh air in the belt lane of the panel (120 m from the doorway of the 120-way gate), where the distance to the supply wind was shorter than $2000 \mathrm{~m}$. The air distribution at the local fan was $668 \mathrm{~m}^{3} /$ $\mathrm{min}$, and wind speed without the fan was no less than $0.25 \mathrm{~m} / \mathrm{s}$. During excavation, an external boring machine spray and the airborne FSZ-type wind and water jet dust collector were used to reduce the volume of dust. In addition, watering was regularly carried out to reduce dust. The purified water curtain was opened in a timely manner during cutting and the coal wall was scoured afterward.

\subsection{Experimental method}

The test to monitor dust concentration its distribution in the heading roadway of the mine featured a $127 \mathrm{~V}$ feeding device, a KDW127/12B power supply, KJ839-F sub-station, a dust concentration sensor, junction box, power 
supply, and signal transmission cable. The connection mode of the device is shown in Fig. 1.

Before underground installation, the operational capability and stability of the equipment were tested on the ground, and all devices were fully connected. In case of continuous live operation for $72 \mathrm{~h}$, observation sensors, and monitoring sub-stations functioned well. Figure 2 shows the layout of the dust concentration sensor in the roadway section. Sensor 1 was $1 \mathrm{~m}$ from the top plate and right side, sensor 2 was placed $2.5 \mathrm{~m}$ from the top plate and $1 \mathrm{~m}$ from the right side, sensor 3 was $1 \mathrm{~m}$ from the top plate and $3 \mathrm{~m}$ from the right side, sensor 4 was $2.5 \mathrm{~m}$ from the top plate and $3 \mathrm{~m}$ from the right side, and sensor 5 was $1.5 \mathrm{~m}$ from the top plate and $4.5 \mathrm{~m}$ from the right wide. During the field test, the sensors were fixed as the working surface advanced. This was equivalent to testing dust concentrations at different distances from the working surface.

\section{Results of field experiment and analysis}

\subsection{Analysis of test of total dust}

Total dust refers to dust that can enter the entire respiratory tract (nose, throat, throat, thoracic bronchus, bronchioles, and alveoli). Respirable dust refers to dust containing particles an aerodynamic diameter smaller than $7.07 \mu \mathrm{m}$ and aerodynamic diameter of $5 \mu \mathrm{m}$, with a collection efficiency of $50 \%$. According to the method of testing described above, data for on-site dust concentration were collected at every two minutes. Sensor 3 failed during the test. According to subsequent analysis, this impeded the field operation, and caused interruptions in signal transmission. The results of the sensor test are shown in Fig. 3.

An intuitive analysis of the result in terms of total dust measured by the five sensors shows that the total dust concentration at a fixed point was not uniform, but fluctuated drastically with such factors as working procedure and construction stops for excavation. The maximum concentration exceeded $800 \mathrm{mg} / \mathrm{m}^{3}$ and the concentrations of the sensors may have been offset to some extent.

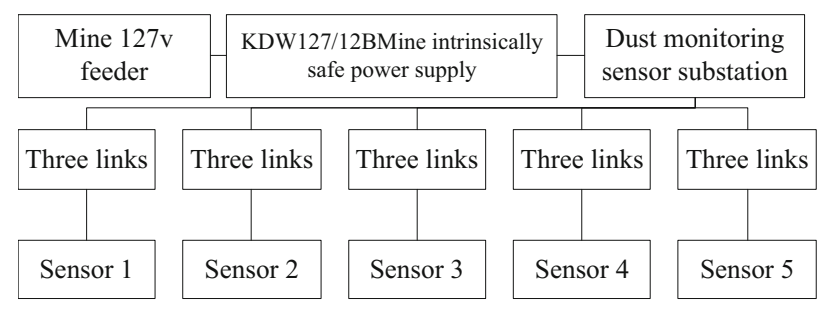

Fig. 1 Connection structure of the sensor
From May 11 to 13 during the test, the range of fluctuation and intensity of total dust were the largest. In this period, the tunneling distance was $25 \mathrm{~m}$, and there was no significant decrease in dust concentration, mainly owing to the disorderly wind flow driving its chaotic movement. Continuous dust deposition and secondary elevation were observed, but its maximum concentration and distribution did not decrease significantly. After May 14, the total dust concentration began to decrease significantly and then gradually. After May 15, the test total dust concentration did not exceed $200 \mathrm{mg} / \mathrm{m}^{3}$, and the tunneling distance was $40 \mathrm{~m}$

It can be concluded from the above analysis that under the influence of high-speed and turbulent air flow in the heading face, the total dust in the tunneling roadway fluctuated sharply 0-25 $\mathrm{m}$ from the heading face, but its peak value and concentration distribution did not decrease significantly. Then, 25-40 $\mathrm{m}$ from the heading face was an area where dust mainly composed of large particles had settled rapidly, and the total dust concentration began to decline rapidly. Beyond $40 \mathrm{~m}$ was an area of gentle subsidence, where most large particle dust settled, and the total dust concentration dropped gently. The results of partitioning are shown in Fig. 4.

According to the test data collected, and combined with the ratio of respirable dust to total dust at different positions as obtained by the dust sampler, the results for respirable dust were obtained and are shown in Fig. 5.

A visual analysis of the results for respirable dust obtained by the five sensors shows that its concentration at the fixed point of the tunneling roadway was uneven and gently changing, affected by such factors as different working procedures for excavation and halts in construction. However, compared with the total dust, the change

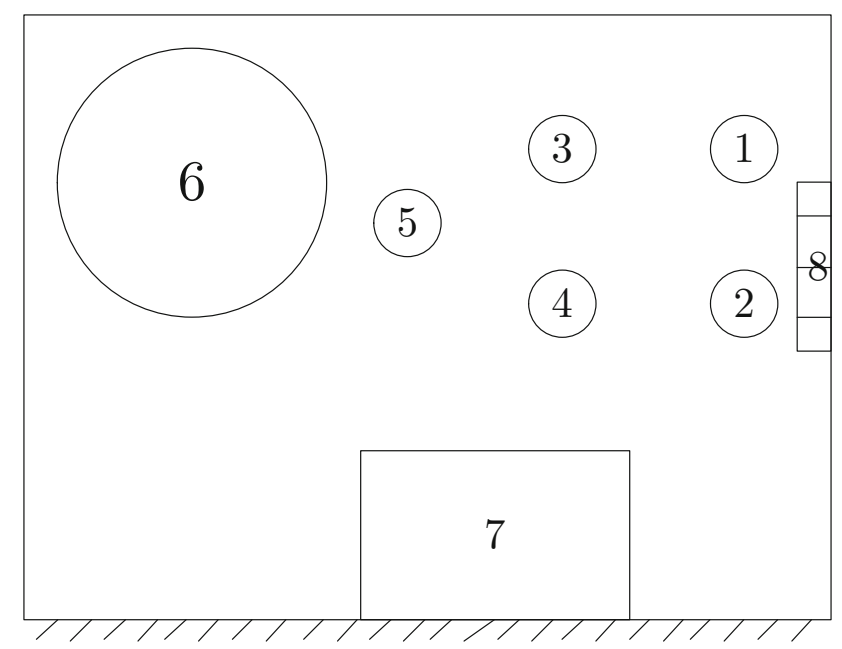

Fig. 2 Arrangement of sensors to measure dust concentration in roadway excavation: 1-Sensor 1. 2-Sensor 2. 3-Sensor 3. 4-Sensor4. 5-Sensor 5. 6-Air cylinder. 7-Tape conveyor. 8-Cable 

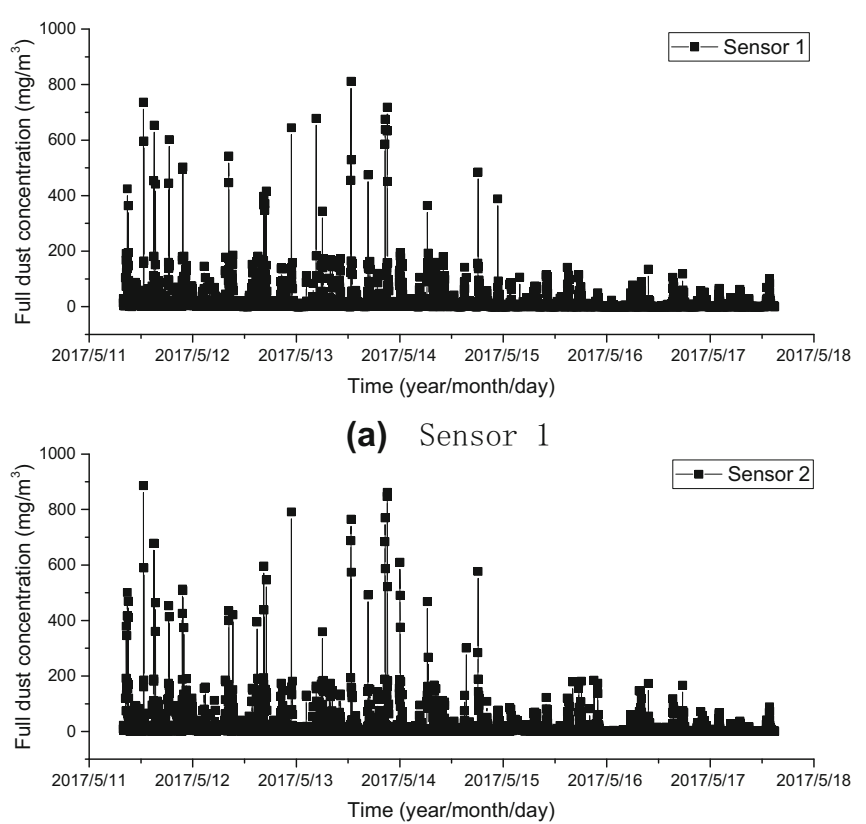

(b) Sensor 2

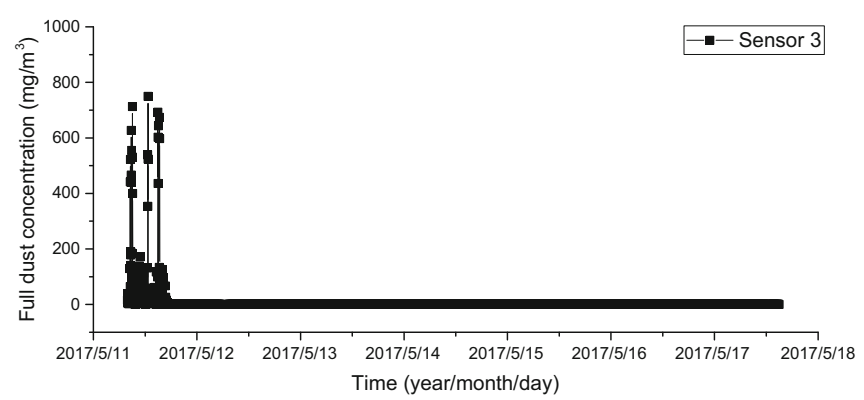

(c) Sensor 3

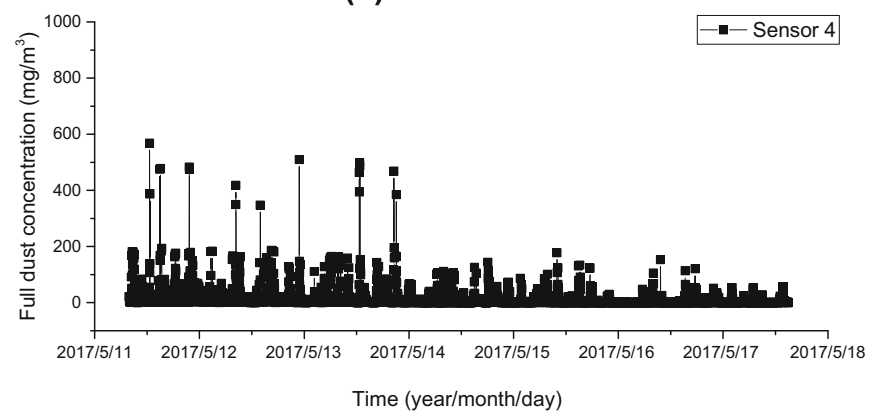

(d) Sensor 4

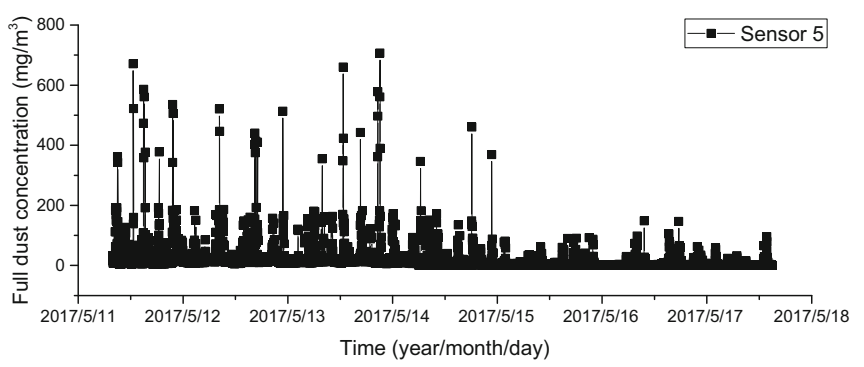

(e) Sensor 5 
4Fig. 3 Total dust concentration changing with time, measured using the sensors

was much more gentle, and the difference was small, with the maximum concentration exceeding $200 \mathrm{mg} / \mathrm{m}^{3}$.

From May 11 to May 13, the range of fluctuation and degree of acuteness of respirable dust were the largest. About $25 \mathrm{~m}$ from the heading face, during violent fluctuations in the concentration of respirable dust, the concentration of its emission did not decrease but increased slightly, which means that continuous dust deposition and secondary uplift were accompanied by the deposition of large particles, and the uplift was mainly respirable dust. After May 14, the concentration of respirable dust began to decrease significantly but the overall process of reduction was consistent. Although the trend of decline was slightly different before and after May 15, there was no significant stage change characteristic similar to that in the process of deposition of total dust. After $40 \mathrm{~m}$, the concentration of total dust did not exceed $75 \mathrm{mg} / \mathrm{m}^{3}$.

It can be concluded from the above analysis that under the influence of high-speed and turbulent air flow in the heading face, respirable dust in the tunneling roadway underwent a sharp area of fluctuation $0-25 \mathrm{~m}$ from heading face, and its concentration in this zone fluctuated violently. More than $25 \mathrm{~m}$ from the head, the concentration of respirable dust began to decrease gradually. The demarcation point was about $40 \mathrm{~m}$ from the head, and its first half was slightly steeper than the second. The results of partitioning are shown in Fig. 5.

The results of the dust field test on Tingnan coal mine have been described above. To explain the characteristics of dust distribution clearly, distributions for different types of dust at different locations and working procedures in the test were analyzed.

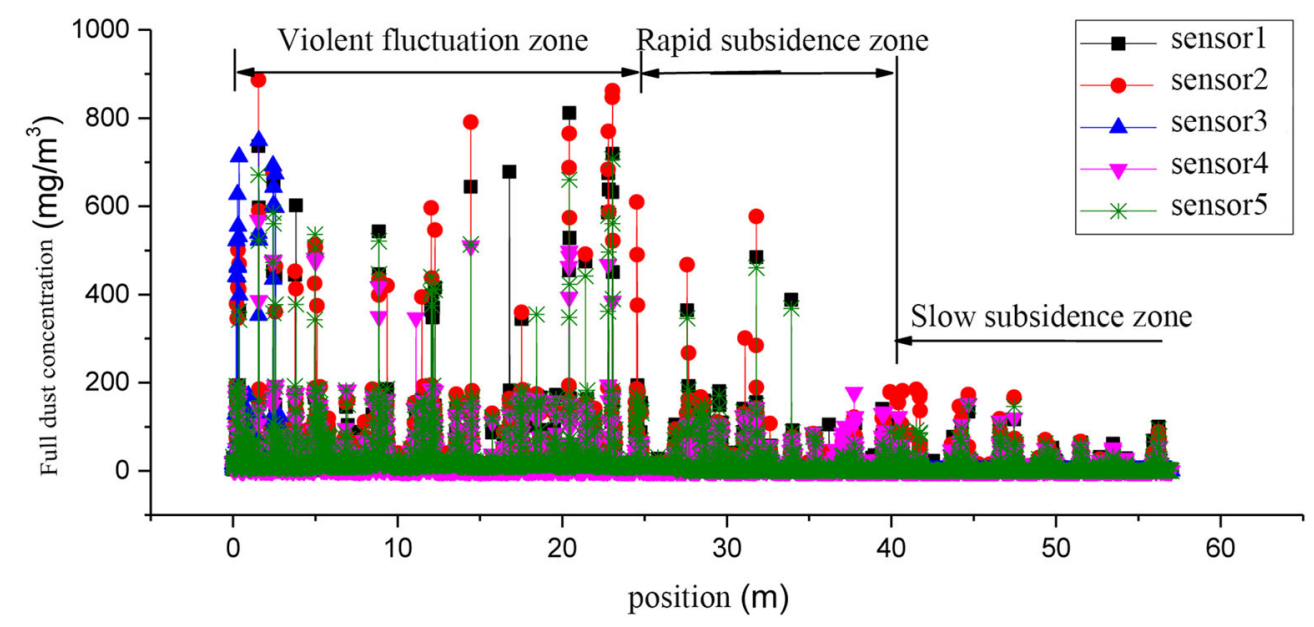

Fig. 4 Division of areas of total dust concentration

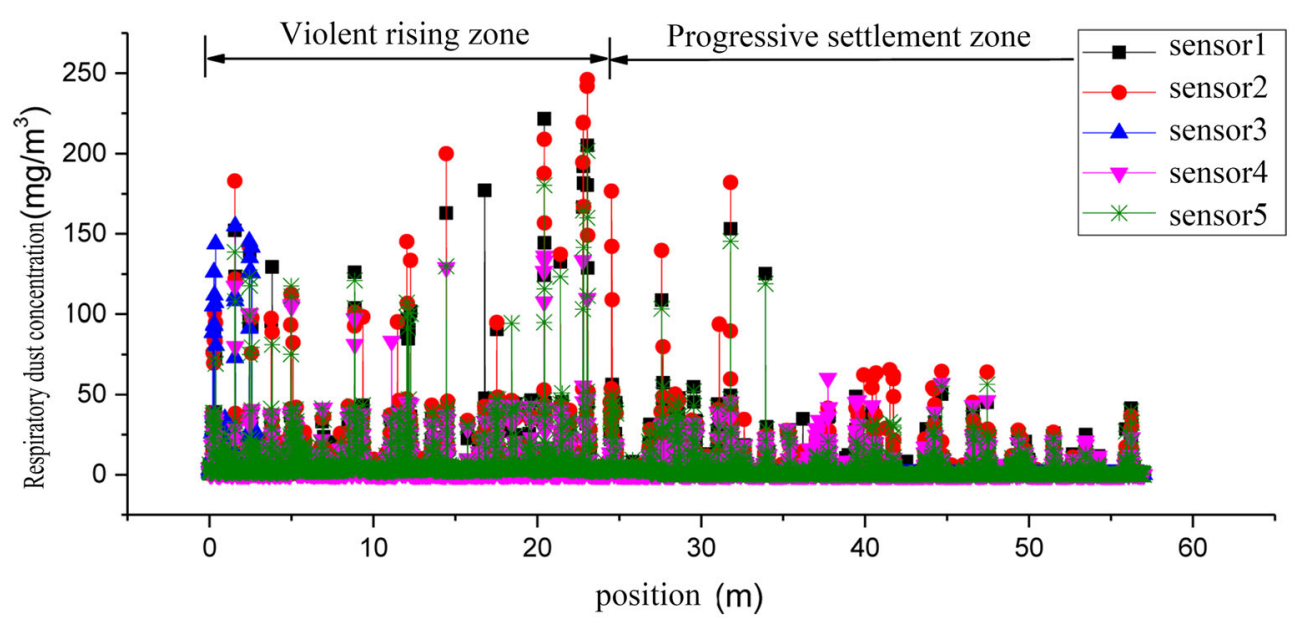

Fig. 5 Division of area where respirable dust was concentrated 


\subsection{Analyzing characteristics of distribution of dust types}

Characteristics of the distributions of total dust and respirable dust along the path were compared and analyzed, as shown in Fig. 6.

The figure shows that respirable dust and total dust exhibited similar trends of change. In the initial test stage, the total dust concentration represented by the black square in the figure was above that of respirable dust, represented by the blue triangle at each corresponding point. The black square gradually moved down compared with the blue triangle, which eventually rose above the black square. Considering that the scale value of respirable dust was 0.28 times that of total dust, respirable dust accounted for less than $28 \%$ of the total concentration of dust in the initial stage, and then increased to more than this. According to the results of numerical calculation, the initial respirable dust accounted for $19.85 \%$ of all dust, and the highest value of respirable dust was $41.42 \%$ in the final test. These results show that large dust particles settled first while small particles were slower to do so.

\subsection{Analyzing characteristics of dust concentration across working procedures}

To analyze changes in dust concentration under different working procedures, the results for a given day were used for targeted analysis and explanation. The results of sensor 1 on May 14 and 16 are shown in Fig. 7.

Figure 7 shows that throughout the procedure, dust concentration generated by the heading operation was the highest, far higher than that generated by other operations. This can be clearly distinguished by observing the level of dust. Because the heading operation was not continuous, and given that such factors as the dust affecting the line of sight and changes in position should be considered in the heading process, the high concentration dust in the tunneling process was intermittent. Due to air flow, humidity, tunneling strength, and differences in local coal bodies, the concentration of dust flow was neither continuous nor high, as in previous studies. A certain amount of dust was generated through coal collection and support operations, but its concentration was much lower than that in tunneling operations. Coal collection and support were generally carried out before and after one or a group of tunneling operations. Moving the heading machine, the small belt, and adding an air duct also produced some disturbance due to wind and dust. The dust concentration in the tunneling roadway was calculated using the background value, which reflected the dust concentration when no operation or simple maintenance was ongoing. As for the Tingnan mine, the background value of dust concentration within $100 \mathrm{~m}$ of the heading face was between 0.5 and $3 \mathrm{mg} / \mathrm{m}^{3}$. Higher background values were obtained closer to the heading face.

\subsection{Analyzing characteristics of dust concentration at different locations}

The distribution characteristics of dust concentration at different locations reflected the situation at different distances from the heading face in the same section. To better illustrate the problem, the average value of dust concentration measured during tunneling over 20 shifts in 7 days during the test was taken as the object of investigation, as shown in Fig. 8.

(1) At different distances from the head, dust concentration was affected by the opposing processes of dust deposition and raising. The total dust reflected a process of "violent oscillation-rapid descent-stable descent" while respirable dust exhibited one of "fluctuating rise-gradual deposition." The settlement and secondary elevation of dust were mainly caused by the disorder in rapid airflow near the head, and the total dust settlement and elevation appeared to be somewhat stable, characterized by oscillation. A smaller amount of respirable dust settled than was elevated, and was characterized by oscillatory ascent. Once airflow had stabilized, the concentrations of both the total and the respirable dust began to decrease. However, due to the inclusion of large particles of dust, the total dust decreased rapidly first, and then the reduction rate dropped, while the slope of reduction of respirable dust was much smaller.

(2) The relation between dust concentration at different positions of the same section shows that total dust and respirable dust followed a consistent rule mainly because the ratio of respirable dust to total dust in the same section was the same. Sensors 1 and 2 were first analyzed. They were placed on the pedestrian sidewalk: Sensor 1 was placed on top of the roadway while sensor 2 was placed $1 \mathrm{~m}$ from sensor 1 . By comparing the concentrations recorded by sensors 2,4 , and 5 , it is clear that although the three measuring lines all fluctuated, except at particular points, the concentration recorded by sensor 2 was the largest, followed by sensor 5, and the concentration recorded by sensor 4 was the lowest. This indicates that the concentrations of dust on the sidewalk and air duct along the roadway were slightly higher than that in the middle. At the same time, changes in the concentration of dust according to sensor 5 in the later stage were gentler than those at the other measuring lines, and the decrease in concentration was slower due to the influence of the air ducts and secondary dust due to coal transport machinery. But this effect was reflected only in the later stage, and its overall influence was minor. 


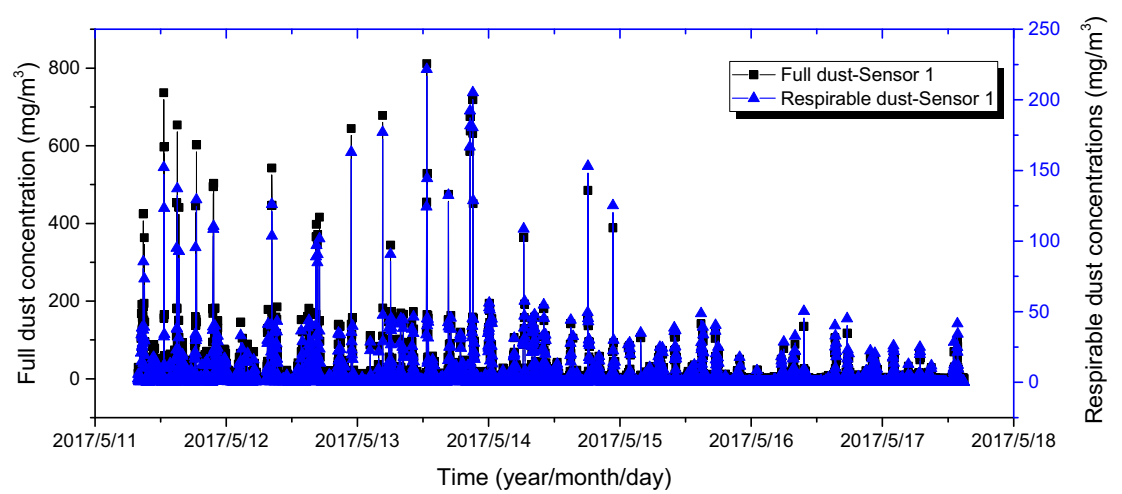

(a) Sensor 1

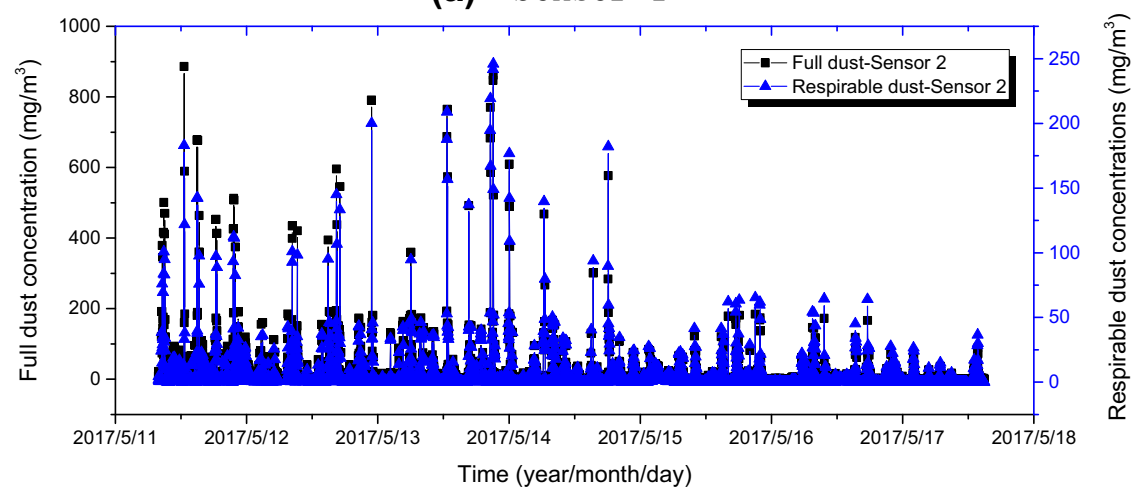

(b) Sensor 2

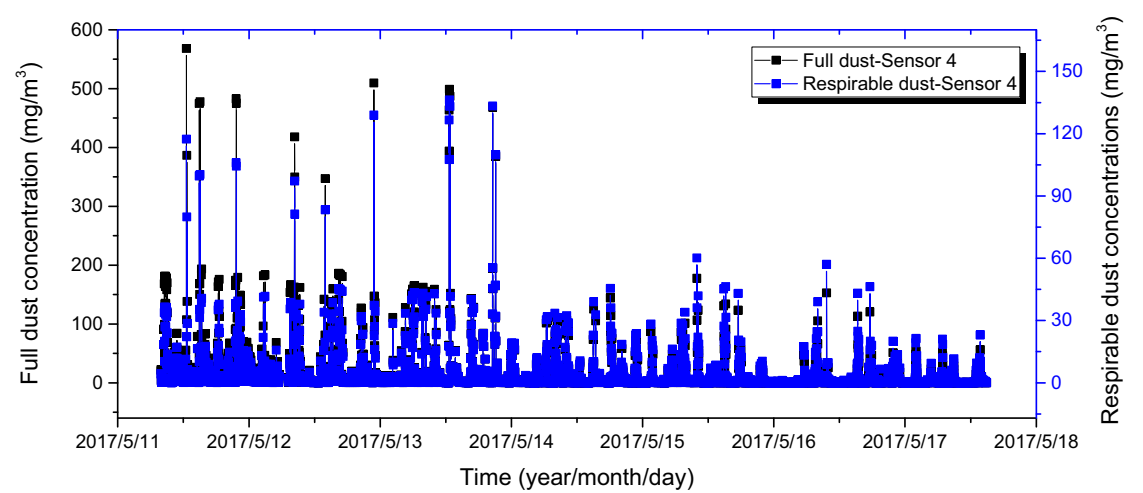

(c) Sensor 4

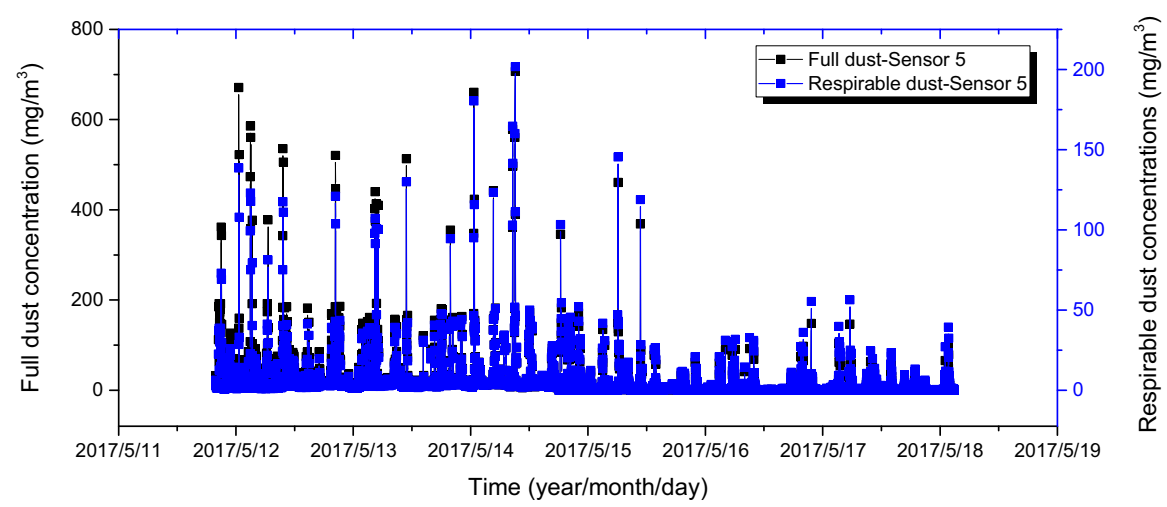

(d) Sensor 5 
4Fig. 6 Comparison of characteristics of total dust and respirable dust over time

\section{Conclusion}

A system to monitor dust online and in real time was used here for field tests to monitor dust concentration at multiple points in the same section of a tunneling working face in the Tingnan mine in Changwu, Shaanxi Province. The conclusions are drew as below:

(1) The dust concentration in the tunneling roadway at fixed points did not change evenly and gently, but showed drastic fluctuations as affected by such factors as different mining procedures and construction stops. There was a sharp fluctuation zone $0-25 \mathrm{~m}$ from the heading face, but the peak value and concentration distribution did not drop significantly. About $25-40 \mathrm{~m}$ from the head was an area of high speed subsidence of the total dust, where large particles mainly precipitated rapidly, and total dust concentration began to decrease rapidly. Beyond $40 \mathrm{~m}$ was an area of gentle subsidence, where most large particles of dust had subsided and the total dust concentration decreased gently. In terms of respirable dust, there was a sharp fluctuation zone $0-25 \mathrm{~m}$ from the head. Beyond $25 \mathrm{~m}$, the concentration of respirable dust began to decrease gradually, and the difference in trend was relatively minor: It was gentler than the reduction in total dust. The boundary was $40 \mathrm{~m}$ from the head, and the first half was slightly steeper than the second.

(2) Through field tests, the distribution characteristics of dust in the tunneling roadway under different dust types and working procedures, and at different locations were obtained. The trends of change of respirable dust and total

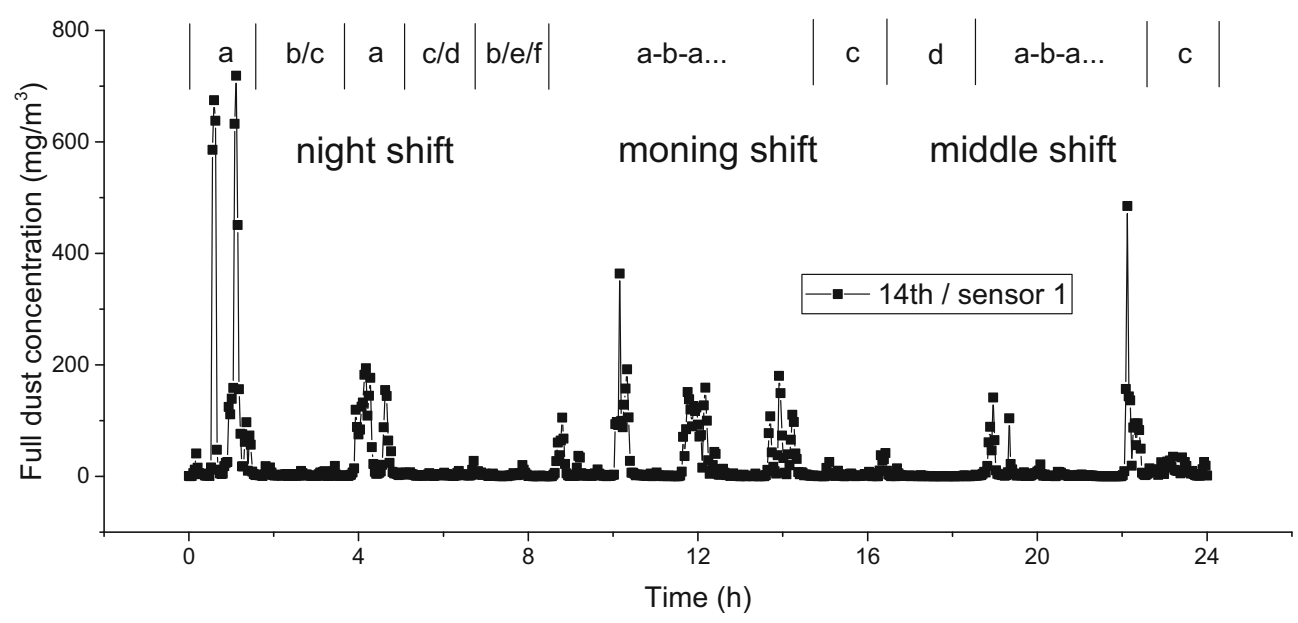

(a) Sensor 1 on May 14

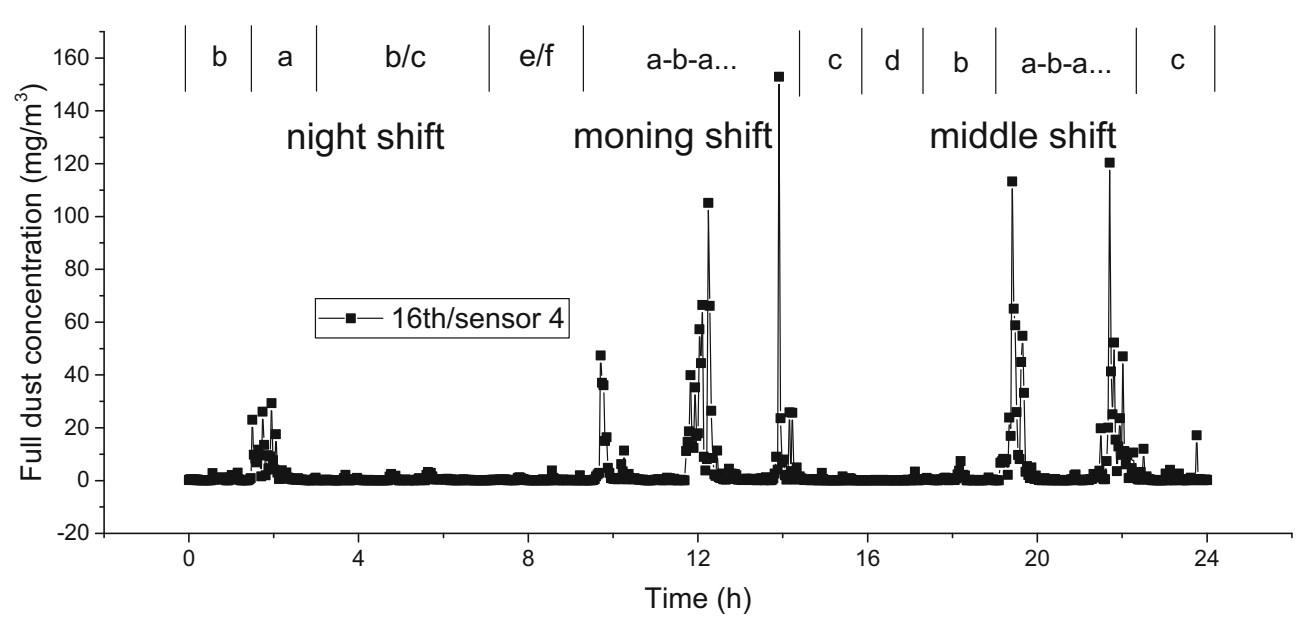

(b) Sensor 4 on May 16

Fig. 7 Single-day total dust concentrations and process control a Mining. b Collecting coal. c Support. d Overhaul. e Shifting machine. f Air cylinder 


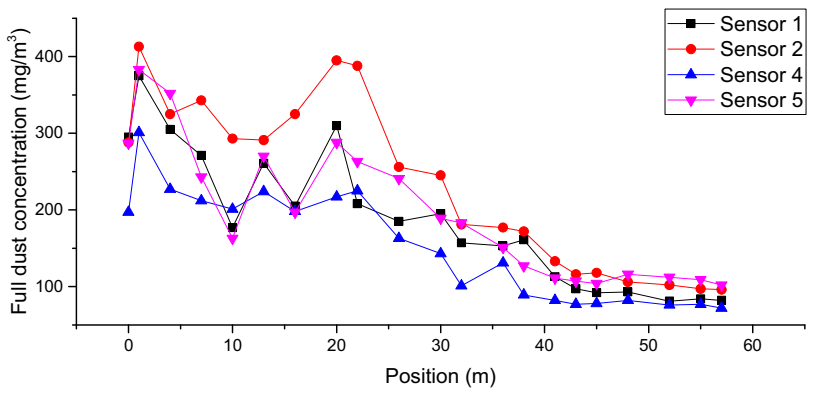

(a) Total dust

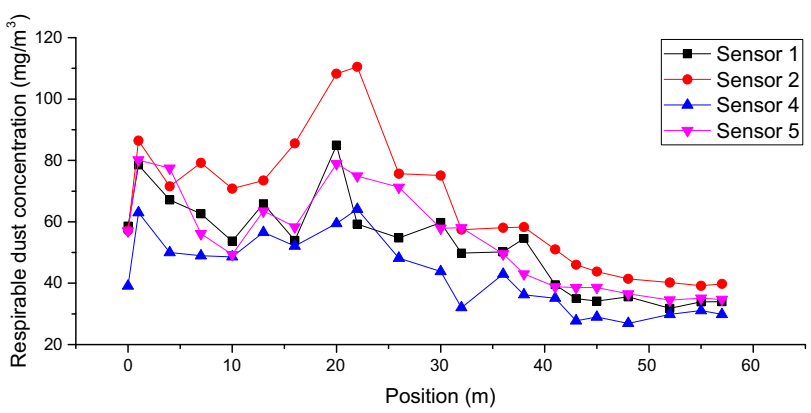

(b) Respirable dust

Fig. 8 Single-day total dust concentration and process control

dust were similar, and the ratio of the former to the latter increased with distance from the heading face. The ratio of respirable dust in the initial section was $19.85 \%$, and its maximum ratio in the final section was $41.42 \%$. In the process of heading, coal collection, support, air duct addition, mobile tunneling machine, and addition of a small belt, the dust concentration generated by driving was the highest, far higher than that due to other working procedures. Because driving was not always continuous, the high concentration of dust generated during it was intermittent, and coal collection and support were generally offered around one or a group of vehicles driving, mobile driving machines, small belts, and the addition of air ducts also produced some disturbance due to wind and dust. The dust concentration was calculated on the basis of the background value. At different distances from the head face, the dust concentration was affected by opposing process of dust deposition and raising. The total dust showed a process of "violent oscillation-rapid decline-steady decline" while respirable dust shows one of "oscillation ascentgradual decline." The relation between dust concentrations at different positions of the same section, and between the total dust and respirable dust followed a consistent rule in this respect. The results shows that dust concentration near the wall was low, and that along the sidewalk and air duct was slightly higher than in the middle. Dust concentration in air duct later on was smaller than in the rest of the test lines, and decreased more slowly.
Open Access This article is licensed under a Creative Commons Attribution 4.0 International License, which permits use, sharing, adaptation, distribution and reproduction in any medium or format, as long as you give appropriate credit to the original author(s) and the source, provide a link to the Creative Commons licence, and indicate if changes were made. The images or other third party material in this article are included in the article's Creative Commons licence, unless indicated otherwise in a credit line to the material. If material is not included in the article's Creative Commons licence and your intended use is not permitted by statutory regulation or exceeds the permitted use, you will need to obtain permission directly from the copyright holder. To view a copy of this licence, visit http://creativecommons. org/licenses/by/4.0/.

\section{References}

Descamps I, Harion J-L, Baudion B (2005) Taking-off model of particles with a wide size distribution. Chem Eng Process 44:159-166

Ghose MK, Majee SR (2000) Sources of air pollution due to coal mining and their impacts in Jharia coalfield. Environ Int 26:81-85

Hou YG, Liu ZP, Cui C (2006) Application of dust monitoring system in coal mine enterprises. Min Technol 6(3):426-428

Hu FK, Shi GQ, Zhang YK et al (2013) Study on dust transport law of long-pressing and short-drawing tunneling based on unsteadystate DPM simulation. China Coal 39(12):104-108

Jiang ZA, Jin LZ, Yuan XZ et al (2001) Experimental research on dust distribution in tunnels. Coal Sci Technol 29(3):43-45

Lu XX, Wang DM, Ren WX et al (2012) Research and analysis of dust generation mechanism and dust migration law. Coal min 17(5):19-22

Nie BS, Li XC, Yang T et al (2013) Distribution of PM2.5 dust during mining operation in coal workface. J China Coal Soc 38(1):33-37

Qin YP, Jiang ZJ, Zhang MM et al (2014) Simulation and measurement comparison of dust movement law in comprehensive excavation. J Liaoning Tech Univ (Nat Sci Ed) 3:289-293

Wang J, Levy EK (2003) Particle motions and distributions in turbulent boundary layer of air-particle flow past a vertical flat plate. Exp Therm Fluid Sci 27:845-853

Witt PJ, Carey KG, Nguyen TV (2002) Prediction of dust loss from conveyors using computational fluid dynamics modeling. Appl Math Model 26:297-309

Yao HF, Jin LZ, Ou SN et al (2009a) Study on characteristics of respirable dust in coal mine based on full shift. China Saf Sci J 19(1):125-131

Yao HF, Wei CG, Jin LZ et al (2009b) Determination and analysis of coal dust deposition intensity in mines and research on prevention and control measures. Saf Coal Min 40(11):13-16

Yao YJ, Cheng WM, Nie W et al (2011) Numerical simulation of dust concentration distribution in the integrated excavation face. Min Saf Environ Prot 38(3):21-22

Yao HF, Deng ZG, Li JL et al (2014) Numerical simulation of air flow movement and dust migration law in exhaust ventilation. Coal Min Technol 19(5):96-99

Zhang JJ (2012) Study on dust transport law and high pressure spray dust reduction technology in Dongrong No. 2 Mine. Liaoning University of Engineering and Technology, p 22

Zou CF, Liu Y, Ma W et al (2014) Study on dust generation and migration of integrated excavation face. Min Saf Environ Prot 41(6):26-28 